\title{
How Digital Platforms with a Social Purpose Trigger Change towards Sustainable Supply Chains
}

\author{
Anika Schroder \\ Copenhagen Business School \\ asc.digi@cbs.dk
}

\author{
Günter Prockl \\ Copenhagen Business School \\ gp.digi@,cbs.dk
}

\author{
Ioanna Constantiou \\ Copenhagen Business School \\ ic.digi@cbs.dk
}

\begin{abstract}
While digital platforms have been intensively researched, there has been little investigation into their role in sustainable change. Our study focuses on food supply chains and food waste and sustainable challenges. Using data collected from exploratory case studies of digital platforms and traditional actors in the food industry of a Nordic country, we categorized three major sustainable platform types: Alterationist, Redistributor, and Capability Builder. We view these as "Zebras," a business serving profit and social purpose, and observe their emerging role in the food supply chain. We also identify key dimensions of governance and sustainability impact. With this study, we investigate how digital platforms contribute to sustainable change while also retaining their profit focus.
\end{abstract}

\section{Introduction}

"Capitalism. Time for a reset" is the new agenda from the Financial Times stating that businesses must make profit but should also serve a purpose [1]. Capitalism as a system has proven to be remarkably efficient in engendering economic growth and lifting people out of poverty. By changing the measurements of our economic progress, capitalism can also be used for the improvement of other social and environmental causes [2]. We have entered an age of "sustainable capitalism transition" [3] often referred to as the triple bottom line (TBL), which pushes benefits to humanity and the planet to the forefront, in addition to financial profit. The TBL approach guides and informs the full and multifarious impact of a business [4] and requires more in-depth research about sustainable business models.

Research about sustainable business models in a digital context is particularly required: Numerous industries are with fundamental changes in supply chains due to the rapid adoption of digital technology [5]. These structural changes alter the traditional, vertical relationships within companies and industries as the roles and capabilities of supply chain participants begin to blur.

Each industry is affected differently, but vertically integrated businesses overlap as competitive threats arise from new digital players. The underlying vertical complexities coupled with the informational intensity of products and services and the reduction of search costs are contributing to disintermediation [6].

Digital platforms are particularly prone to disintermediate and disrupt existing supply chains. When looking at the "unicorn" list (start-ups valued over one billion dollars), nearly 20 percent are platform businesses [7].

As 'unicorns' are known for their 'traditional capitalistic' approach: bending on disruption, emphasizing quantity over quality and consumption over value creation [8] there is space for new business models. Space is created for 'zebra' companies: profitdriven businesses with the intent to improve society. They won't sacrifice one for the other. They have capital efficiency. Zebras are mutualistic: they collaborate and protect each other, resulting in a stronger collective output [8], [9].

This study aims to investigate 'zebras' and answer the following research questions: What are the types of digital platforms with a social purpose (zebras) in the food industry and how do they impact the food supply chain?

The corporate movement toward 'zebras' marks a new type of digital platform that combines a social purpose with a commercially sustained business model. We study best practice examples of the food industry in the context of the sustainable business archetype 'creating value from waste' [10]. We explore how digital platforms within the food supply chain are tackling suboptimal processes and also eliminating wasteful behavior by internalizing a societal goal. We identify three different types of digital platforms with a social purpose that have different influences on the 
food supply chain. These are Alterationist, Redistributor and Capability Builder.

The paper will first explore the theoretical background of digital platforms and sustainable business models. Then, we present the research methods of our analysis and the findings of the study. Next, we discuss the findings and conclude with limitations and further research.

\section{Theoretical Background}

\subsection{Digital Platforms}

The advancement of digital technology has led to new business models, which reshape contemporary economies. One main focus is digital platforms. Although digital platforms are diverse in function and structure, they are often distinct from the traditional pipeline business as they do not buy, produce or sell goods. Instead, they facilitate trade between two or more different groups by providing a digital framework where they shape the rules for participants' interaction [11]. Digital platforms support an array of interactions, which inevitably blur market boundaries. Platform boundaries stretch over several industries, as goods sold through a platform are not limited to any specific sector [12].

The rise of digital platforms does not merely blur market boundaries, it also causes organizational boundaries to blur [5], which makes the outward focus for a business vital [13]. Digital technologies enable product and service co-creation. Digital platforms assume control over resources that are beyond the scope of conventional organizational boundaries [5]. A digital platform's performance is increasingly dependent on its ability to utilize assets outside its direct control. Therefore, it is crucial to possess external resources to foster the collective health of the network.

One of the more important objectives for a digital platform is to exploit network effects. Propelled by increased efficiencies in social networks, demand aggregation, and app development, platforms can build a larger network that holds more value for the users [13]. Nevertheless, the strength of a network is predicated not only on its sheer size, but also on how meaningful and intense a connection is established between users [14]. The network structure does not only impact the speed at which a platform can reach scale, but also influences the organization's ability to sustain that scale. The more a network is fragmented into local clusters, and the more isolated those clusters are from one another, the more vulnerable a business is to challenges [15].

\subsection{Sustainable Business Models in the Supply Chain}

The focus on environmental issues has been viewed as profit decreasing within traditional strategies (e.g. [16], [17]). Recently, new business models have been designed to provide products and services that can be characterized as sustainable and/or socially innovative [18]. Therefore, a more holistic approach when looking into business models can be found in reference to the claim of the triple bottom line (TBL) where the full costs involved in doing business are expressed beyond the traditional measurement of corporate profit [6]. There are three distinct and separate bottom lines that measure a company's success: financial profit, environmental impact, and the organization's social responsibility [19].

The concept of social entrepreneurship integrates the TBL approach with for-profit business models [20]. The social mission, and hence social value creation, is a central priority for these business models. Therefore, promoting sustainable development in order to better serve the planet plays a central role. Moreover, social enterprises see market failures as a business opportunity by addressing the social needs that arise from these failures [21]. One example of creating a business opportunity from market failure can be seen in the sustainable business model archetype 'creating value out of waste' where waste streams are turned into useful and valuable input while also making better use of under-utilized capacity [10]. Other sustainable business model archetypes can be found in Bocken et al. [10].

\section{Empirical Background}

According to the organization Project Drawdown, reducing food waste is the most effective solution to fight against climate change as it would alleviate more than 90 gigatons of greenhouse gases [22]. Food waste is often an underestimated topic when talking about $\mathrm{CO} 2$ reduction even though it produces eight percent of global greenhouse gases, which is almost equivalent to global road transport emissions. Therefore, it has a huge impact on global warming and the future of our society. Reducing food waste is also anchored in Sustainable Development Goal 12 of the UN [23] which makes the topic of food waste a relevant case for our research purpose.

The demand for constant availability of fresh and diverse goods is one of Western countries' market conventions that lays the foundation for waste. The food supply chain is partly to blame as it has traditionally been a push chain. Thus, it contributes to the consumption habits that are costing us today. 
Nevertheless, the industry can be considered to be undergoing a process known as 'chain reversal,' where consumers now dictate to producers what they want to eat [24].

The food supply chain is a rather complex network of heterogeneous entities upstream and a market power consolidation downstream from the middle of the chain. The food and agriculture sectors have been relatively slow to innovate and adopt new technologies, which has created a disparity between investments made in food system start-ups and those made in other sectors such as the health care sector, which receives ten times as much investment [25]. Both heterogeneity and power regimes of the food supply chain further complicate innovative processes. A quick fix has proven to be illusory and increasing the efficiency of the food system will require an extensive, collaborative effort by governments, businesses, and consumers alike.

However, finding where waste exists along the food supply chain provides the opportunity to implement effective solutions. Due to the fact that digital platforms have supplier and consumer market sides, they appear excellently positioned to identify these solutions. Our intention is to research selected food waste platforms that are mitigating market inefficiencies and reflect the push towards a more sustainable food industry. These platforms have the ability to reshape an inefficient food supply chain and show that businesses can gain financial profit and create environmental and social impact.

\section{Research Method}

The present study combines theoretical insights from digital platforms and sustainability driven business models to investigate the impacts that digital platforms with a social purpose create in the food supply chain. The study involves an exploratory, multiple case study [26] of the food industry and the new digital platforms with a social purpose. Our findings presented in this paper provide insights on the different types of digital platforms in the food industry and their potential impacts (so-called dimensions) on the food supply chain.

The data collected includes information from semi-structured interviews, informal conversations, observations and secondary data documents. The data collection period ranged from February 2019 to January 2020. We recorded, transcribed and categorized 15 formal interviews (14 total hours of audio transcribed to 263 pages). The interviews were conducted according to a purposive sample with industry representatives of the traditional food supply chain (large scale farmer, supply chain director of a leading supermarket chain, and R\&D Manager of the most sustainable restaurant 2019) and with founders and employees of five food waste platforms (Fresh.Land, GRIM, DelDinMad, TooGoodToGo, Plant Jammer).

The sampling of the studied platform was based on identifying cases of the categories proposed by Aschemann-Witzel et al. [27] (a detailed explanation of the research can be found in 5.1). By looking at the platforms' business model and performing a business model analysis [28], [29], the platforms were then put into three categories: Alterationists, Redistributors, and Capability Builders. Additionally, we gathered data from secondary sources such as newspaper articles, websites, blogs, social media as well as industry reports (153 documents). Our findings were then triangulated with secondary sources [30].

A theory driven thematic analysis through template coding was employed and Nvivo was used for the coding process [31]. The data went through three rounds of coding. The first round followed the template based on a theory driven interview guide. A set of themes such as business model, impact, platform dynamics, supply chain dynamics were defined based on the template before the researchers independently processed and analyzed the data. After each round, the findings were discussed between the researchers and new codes emerged that formed a new template. The new template included the main themes such as control, rivalry and economic, social and environmental impact. This process was highly iterative until the final codes emerged or were extended based on the initial template.

\section{Analysis}

\subsection{Classification Frameworks}

In platform literature there have been several attempts to categorize platforms into types. We will focus on the theoretical framework of Constantiou, Marton \& Tuunainen to explain platform and market governance [5]. The framework consolidates into four platform models for the sharing economy based on two dimensions: One dimension refers to high vs. low rivalry between platform participants. The other refers to the control (loose/tight) exerted by platform owners to platform participants. The rivalry dimension is described by the market coordination mechanism as it is induced by the platform owner. The control dimension is described by extending organizational coordination mechanisms into the platform's user base.

Chaperones and Franchisers foster high rivalry by recommending the price for the service based on realtime changes in supply and demand. Gardeners and 
Principals foster low rivalry among platform participants, for instance, by allowing them only to barter for a share in the costs of the service or only to exchange gifts. Franchisers and Principals exert tight control over platform participants (e. g. standardizing procedures and issuing contracts). Chaperones and Gardeners exert loose control over the platform (e.g. participants rewarding socially acceptable behavior and setting social norms and community values) [5].

Governance is also an important factor in supply chain management. Gereffi et al. refer to governance and actors' positioning in the supply chain (e.g. focal actor with captive suppliers) using power asymmetry and coordination requirements [32]. Kraljic classifies relationships based on market complexity and strategic impact related to sourced materials [33]. Therefore, we extend the rivalry dimension of Constantiou, Marton \& Tuunainen framework [5]. One form of rivalry remains the market coordination mechanism across platform customers as mentioned in their framework. However, we will extend rivalry by the coordination mechanism within and across the supply chains.

Additionally, to understand a concrete empirical example of sustainable business models, we will focus on digital platforms in food supply chains. In food supply chains, commodity chains are distinguished from alternative food networks. The latter compete based on new conventions in regard to quality and sustainability awareness [34]. Bocken et al. separates sustainable business model archetypes [10]. To link platform businesses with more concrete sustainability goals we narrow the focus on waste reduction.

For food supply chains, Aschemann-Witzel et al. identified three general types of initiatives that aimed at tackling waste. These initiatives are distinguished by their key characteristics and focal proposition for successful waste reduction: (1) retail and supply chain alteration initiatives focus on actions that prevent or avoid food waste within the supply chain; (2) redistribution initiatives tackling food waste across the supply chain by redistributing surplus food to consumers; (3) information and capacity building initiatives such as consumer organizations that target consumers and provide information to consumers in order to build their capacity to directly reduce waste [27].

Connecting the categorization from platform literature with that from (food) supply chain management literature with an emphasis on food waste reduction, we attempt to form and illustrate a new framework for Zebras. Zebras aim at earning profits while simultaneously creating environmental and social impact. In that way they sustain their competitive position while still improving society.
Thus, we analyze types of Zebras and their dimension using food waste as an empirical context.

\subsection{Categorization of Platform Types}

To understand the potential impact and changes in the food supply chain, we first show how the digital platforms are positioned in the food supply chain, seen in Figure 1. Then, we categorized the platforms based on Aschemann-Witzel et al. framework into three categories [27]. The three sustainability dimensions (economic, environment, social) reflect the emphasized value proposition of the respective model [6]. This is in a later stage (5.3) linked to Constantiou's et al. categorization of platforms. The related dimensions control and rivalry reflect the conditions for value capturing [5].

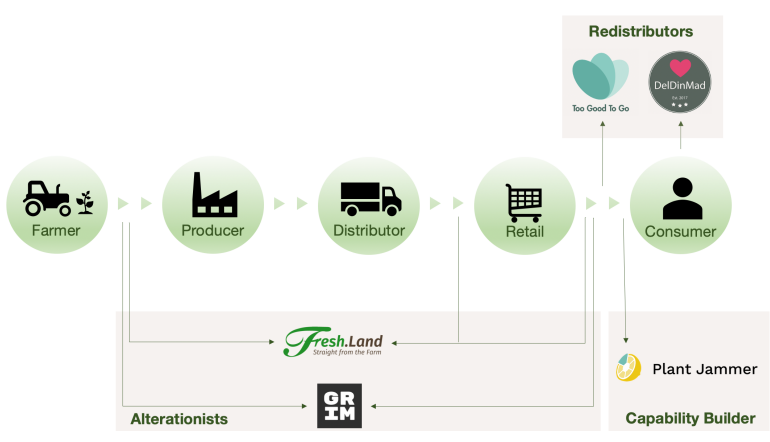

Figure 1. Digital Platforms in the Food Supply Chain

5.2.1. Alterationists. Alterationists propose a shift to alternative food supply chains which are shorter and enable consumers to buy fresh produce directly from farms. Through their platform properties, they accumulate demand and actively match suppliers with buyers. Fresh.Land (Alterationist 1) and GRIM (Alterationist 2) are classified in this category.

Alterationist 1 was founded in February 2015 and their mission is "to change the food industry and bring access to fresh and natural products from farmers bring the 'farmers markets' to the supermarkets." Alterationist 1 sources fresh, high-quality produce from producers and delivers it directly to buyers. It effectively shortens the supply chain by cutting out middlemen while also cutting food waste and chemicals through reduced transport logistics.

Alterationist 2 was founded in July 2018 and their mission is "to create a new quality standard of what is edible and to show people how beautiful and tasty ugly can be". Alterationist 2 deals with produce, primarily fruits and vegetables, that do not match industry 
standards based on appearance. They provide this produce through a one-off purchase or a subscription service to consumers and restaurants. Alterationist 2 could also be seen as a redistributor, however, because it is a direct distribution from producer to consumer, they are more actively altering traditional supply chain dynamics without necessarily redistributing their surplus product to new sources.

The operations we described for these companies fit in the category of Alterationists as they effectively shorten the supply chain by cutting out middlemen while also cutting food waste. As market power typically concentrates in the center of the supply chain - wholesalers, processors and retailers - these platforms enable smallholders to compete and apply fairness as means toward economic, environmental and social impact on the local community.

5.2.2. Redistributors. Redistributors facilitate the redistribution of surplus food. In a platform context, they act as a marketplace where one side of the participants provide the physical resources that the other participants can pick up offline. TooGoodToGo (Redistributor 1) and DelDinMad (Redistributor 2) are classified in this category.

Redistributor 1 was founded in September 2015 and their mission is: "to reduce food waste worldwide, and our vision is to create a world where food produced is food consumed". Redistributor 1 is a digital marketplace offering restaurants and bakeries a way to sell surplus food to consumers at discounted prices instead of having the establishment dispose of the food as waste. Redistributor 2 was founded in July 2017 and their mission is "to raise awareness among Danes about sharing our common resources". Redistributor 2 is a not-for-profit platform that opens channels between consumers to share their surplus food. It enables direct contact between consumers, where users can see different types of food being posted on the platform for pickup. At their own discretion, users may choose with whom to trade with.

The operations we described for these companies fit in the category of Redistributors due to their emphasis on redistributing surplus products to end consumers which also creates a new market.

5.2.3. Capability Builders. Capability Builders enable users to establish new capabilities through the use of convenient technology. Plant Jammer (Capability Builder 1) is classified in this category. Capability Builder 1 was founded in August 2016 and their mission is "to reduce greenhouse gas emissions and fight climate change through sustainable cooking and plant-based food". Capability Builder 1 allows consumers to cook and eat more flexibly. Individuals are empowered to reduce waste in their home by using ingredients that would normally be wasted due to the household not knowing how to use them in their daily meals. Thus, Capability Builder 1 creates a business model with AI and human input to add gastronomic knowledge that results in modular recipe creation.

The operations we described for these companies fit in the category of Capability Builder due to their emphasis on providing information and sharing knowledge which builds consumer capabilities to reduce wasteful habits.

\subsection{Dimensions}

In the previous section we illustrated the principal value propositions for three categories of food waste reduction platforms based on Aschemann-Witzel et al. [27]. Turning back to our digital platform framework, we now investigate the requirements for capturing the propositions. This links to the extended dimensions from Constantiou et al.: control and rivalry and the TBL approach for sustainability from Elkington (1998) [3], [6].

5.3.1. Tight or Lose Control by Platform Owner. The Alterationists perform tight control. For example, they carefully handpick the farmers that they onboard, additionally they approve each new product manually. The Founder of Alterationist 1 explains that the "platform takes care of, getting products, matching products from a supplier to a consumer and it handles all the logistics involved in that. So the platform combines three things. It combines the e-commerce component where the deals are made, contracts are made, suppliers and buyers are allocated. It combines the second thing, which is logistics, where we actually control the delivery via last mile or long haul. And thirdly, there's the finance that also goes through the system. So, we do all the payments, all the invoicing, all the credit notes etc., and all the insurance" Thus, Alterationists specify, standardize and monitor all aspects of the platform participation from matchmaking to logistics to payment which are channeled through a single point of control - their digital platform.

Wherever Redistributors have loose control, the sellers are quickly onboarded without much paperwork or certification, as the Community Manager from Redistributor 1 points out: "we are starting to experience that shops contact us and say: 'oh our customers are asking us to use TooGoodToGo can you help us to use it.' and within five minutes they are users of TooGoodToGo." Thus, the Redistributors define only minimum standards. Their coordination is more concerned with supporting platform participation. 
The Capability Builder facilitates loose control by openly sharing data and allowing third parties the ability to access it. Capability Builder 1 has an open IP strategy; they license their software (SaaS) which gives them several advantages as the CTO explains: "we're not going to have access to the users, but we're going to have access to any content they create on this." Thus, the Capability Builder only has guiding principles, their coordination is more concerned about orchestrating platform participation which cultivates communities by providing an infrastructure.

5.3.2. Rivalry of Platform users. Alterationists create profits by buying from farmers at world market prices and delivering directly to the consumer. The company is taking care of all the operations and the consumer has a fixed price. Thus, they foster low rivalry by charging standard prices for the purchased service.

Redistributors redistribute the surplus food to consumers for a highly discounted price compared to original price. The platform of Redistributor 1 for example receives money through a transaction fee for each sale which is one-third of the sale. Thus, Redistributors foster low rivalry among platform participants by allowing them to only barter for a share in the costs of the service or only to exchange "gifts".

The Capability Builder 1 users' pricing is fixed through a subscription model for consumers and licensing service for companies. Prices are not dynamically adjusted to reflect supply and demand but rather are based on predefined, stable categories.

5.3.3. Rivalry in Supply Chain. Alterationists disintermediate and directly compete based on new conventions with traditional (commodity) supply chains. As of now, established players still have strong market power as the Supply Chain Manager from COOP explains: "Of course we have a pretty good bargaining power, because we are the second largest in Denmark (...) we are moving a lot around, especially with the farmers and so on that we are changing from farm to farm every day. So, we are pretty agile there, and, and not that dependent on the single supplier". Alterationists show high rivalry to the traditional supply chain actors through their disintermediation.

The Redistributors, in contrast, utilize the inefficiencies of commodity chains to construct new business models on top. Thus, they stand in moral rivalry to commodity chains' old conventions. "That's a lot of inefficiencies [...] primarily the collaboration between the suppliers and the retailers that's a lot of inefficiencies. And still the sharing of a forecast is relatively low, [...] retailers are really keeping the prices so close to them because of the competitive area in the marketplace." Thus, Redistributors have a higher moral claim, making the old convention struggle and enhancing rivalry.

The Capability Builder has no visible rivalry at the moment as they have an innovative business model that does not directly compete with old conventions.

Naturally, all platform types show rivalry with actors of the same platform type as they are trying to gain more market share. However, between the alternative types is a strong sense of community to build the new conventions. As stated by the Customer Engagement Manager at Redistributor 1, food waste and other climate change challenges have to be tackled as a collective. "Food waste and most of all the problems that we're dealing with right now in terms of climate change are something where people need to work as a community and we want to create that community and all we want is to put a label on fighting food waste and not just earning money on food waste that's being saved" The digital platforms recognize the importance of turning this network into a valuable community. Building the community provides an extra layer to the cross-side network effects between suppliers and consumers.

5.3.4. Sustainability: Business Opportunity, Environmental and Social Impact. The Zebra platforms transform food waste challenges into business opportunities by creating value out of waste streams. However, they do so in different ways: Through altering the supply chain, redistributing waste, or building capabilities to diminish waste.

Alterationists represent a business model that directly connects farmers to consumers and thereby triggers disintermediation, which reduces transport time and cost and lowers food waste and $\mathrm{CO} 2$ emission. These cases disrupt the supply chain. Through their platform properties, they enable aggregation of supply and demand. The aggregation of demand particularly benefits small-scale farmers, who struggle with the changing market environment. "They want to reach directly to the customers, but they don't have the scale to do so by their own brand or have their own distribution channel. That's what we do for them," as the founder of Alterationist 1 states and goes on: "So there is a very clear quality difference when you are on a short supply chain or when you are on the longer one and it's more massive. So, people come to us because of that higher experience, that better quality." Through disintermediation, they aim at all three sustainability dimensions. They create economic impact by establishing a new business model, taking care of the operations and creating profits by receiving a share of sales of the sold produce from the farmer. Environmental impact should result from shorter supply chains which cuts down on transportation costs 
and lowers waste. They create social impact by contributing to farmers' welfare. Smaller suppliers struggle to live on better product quality alone and are in need to reach out to consumers directly - the platform gives them an opportunity to do so.

The Redistributors' business model involves redistribution of food waste. For example, the platform acts as an online marketplace by connecting businesses with surplus food to consumers: "consumers can find and save surplus food and as a business you put up the food that you have at the end of the day that is unsold, but still good," explains the Marketing Manager of Redistributor 1. They create economic impact by creating a business model using the food waste challenge in existing commodity chains as a business opportunity. The platform of Redistributor 1 for example receives money through a share of sales. The environmental impact lies in redistributing surplus food which cuts food waste significantly. The platform creates social impact by bringing awareness and education to consumers about food waste.

The Capability Builder 1 business model sets its focus on building competency, which enables its users to create more sustainable habits through its machine learning technology. The founder of Capability Builder 1 states, "we are trying to use technology to invest in flexibility in people's homes [...] and once you get that flexibility out there - people are empowered. People get to actually cook what they know they should be eating more of and we get this flexibility that enables the whole food chain to be more efficient and better." Capability Builder 1 creates economic impact through a subscription model to premium service and licensing their API to companies. The environmental impact is created by urging people to cook at home and with what they have available, which reduces food waste. The platform creates social impact by bringing awareness to cooking and food waste and attempting to change consumer behavior through gamification and nudging elements.

\section{Discussion}

Our findings revealed that the studied platforms have been able to leverage information technology to create business opportunities that conventional companies have been unable to create. They aim at business opportunities from market inefficiencies or failures and put a social mission at the center of their value proposition. These platforms impact supply chain actors and consumers as well as society as a whole. All of these platforms emphasize social and environmental impact and are searching for holistic solutions by combining all three lines of the triple bottom line.
There is rivalry, but with different strength and scope to the established commodity chains.

Additionally, we found that building and maintaining a platform ecosystem rooted in collaboration is critical for the cases. In order to increase their impact and establish new conventions, they collaborate with each other and other initiatives. We categorized the digital platforms with a social purpose in three groups: Alterationists, Redistributor and Capability Builder. Additionally, six dimensions emerged based on Constantiou et al.'s framework and Elkington's (1998) triple bottom line approach (see Table 1) [5], [6].

\section{Table 1. Dimensions of Zebra Platforms}

\begin{tabular}{|l|c|c|c|}
\hline & Alterationist & Redistributor & $\begin{array}{l}\text { Capability } \\
\text { Builder }\end{array}$ \\
\cline { 2 - 4 } & $\begin{array}{c}\text { Provide } \\
\text { alternative } \\
\text { chain }\end{array}$ & $\begin{array}{c}\text { Redistribute } \\
\text { and utilize } \\
\text { waste }\end{array}$ & $\begin{array}{c}\text { Enable } \\
\text { consumers }\end{array}$ \\
\hline Control & Tight & Loose & Loose \\
\hline $\begin{array}{l}\text { Rivalry } \\
\text { of } \\
\text { platform } \\
\text { users }\end{array}$ & Low & Low & Low \\
\hline $\begin{array}{l}\text { Rivalry } \\
\text { in the } \\
\text { supply } \\
\text { chain }\end{array}$ & $\begin{array}{c}\text { Strong rivalry } \\
\text { to } \\
\text { commodity } \\
\text { chains }\end{array}$ & $\begin{array}{c}\text { Symbiotic to } \\
\text { commodity } \\
\text { chains but with } \\
\text { "moral" rivalry } \\
\text { (parasitical) }\end{array}$ & $\begin{array}{c}\text { No visible } \\
\text { rivalry }\end{array}$ \\
\hline $\begin{array}{l}\text { Economi } \\
\text { c Impact } \\
\text { (Revenu } \\
\text { e model) }\end{array}$ & $\begin{array}{c}\text { Share of } \\
\text { direct sales }\end{array}$ & $\begin{array}{c}\text { Share of } \\
\text { redistributed } \\
\text { sales }\end{array}$ & $\begin{array}{c}\text { Subscription } \\
\text { and } \\
\text { Licensing } \\
\text { sales }\end{array}$ \\
\hline $\begin{array}{l}\text { Social } \\
\text { impact }\end{array}$ & $\begin{array}{c}\text { Fairness } \\
\text { farmer } \\
\text { welfare }\end{array}$ & $\begin{array}{c}\text { Perception } \\
\text { towards food } \\
\text { waste }\end{array}$ & $\begin{array}{c}\text { Changing } \\
\text { consumer } \\
\text { behavior }\end{array}$ \\
\hline $\begin{array}{l}\text { Environ- } \\
\text { mental } \\
\text { impact }\end{array}$ & $\begin{array}{c}\text { Less food } \\
\text { miles but } \\
\text { loss of scale } \\
\text { effects }\end{array}$ & $\begin{array}{l}\text { Utilization and } \\
\text { less food loss } \\
\text { in the supply } \\
\text { chain }\end{array}$ & $\begin{array}{l}\text { Less food } \\
\text { waste at } \\
\text { consumer }\end{array}$ \\
\hline
\end{tabular}

Alterationists build an alternative system. Their control is tight (e.g. through their highly standardizing procedures contracts and they foster low rivalry among platform participants through their fixed prices). Their strong rivalry towards the supply chain comes from their disintermediation. Economically, they are viable through their share of sales revenue model. Socially they benefit the fairness and welfare of farmers and diminish power asymmetries. However, their environmental impact is uncertain: They have loss of scale effects, but the produce is delivered to the 
consumer quicker which might affect the longevity of the produce for the end consumer.

The Redistributors' business model exploits, in a parasitic/symbiotic way, the inefficiencies of traditional commodity supply chains. Although the redistribution of waste does not ultimately fix the underlying problem of food waste, the old conventions' lack of effort looks bad in the eyes of society. We see here a kind of moral rivalry in the supply chain. Redistributors exert loose control (e.g. govern participants through user rating systems, setting social norms and community values) and foster low rivalry among platform participants as they only allow the supply side to receive compensation for their efforts to publish a product in its platform. Economically, they are viable through their share of sales revenue model, while socially, they change the perception towards food waste. Environmentally, they utilize and lower food loss in the supply chain.

The Capability Builder has a completely different approach. They address a problem with a forwardlooking solution, as 50 percent of food waste comes from households. The Capability Builder uses technology to enhance information exchange with consumers that enables them to build sustainable habits. The Capability Builder exerts low control by having a minimum amount of standardization which, in turn, cultivates communities by providing an infrastructure. The rivalry among platform participants is also low as the aim is to orchestrate their efforts to self-organize participants. The rivalry in the supply chain is not of concern as the Capability Builder provides a separated service on top. Economically, they are compensated through subscription and licensing revenue models. Socially, they change consumer behavior and environmentally, they help to generate less food waste at a consumer level.

Additionally, all platforms build a community around raising awareness of food supply chain inefficiencies. Raising awareness about the environment and, in particular, food waste is manifested in new conventions towards quality of food and the related means of supplying it [34]. This fosters rapid development of alternatives within or next to the traditional commodity chains and builds the foundation for the value proposition of the new platforms. The investigated platforms do not look for unmet needs, they look for problems and consequences that need to be solved, which is typical for 'zebras' [8]. They focus on profit but display a triple bottom line approach [6]. The awareness of social and environmental consequences can also lead to new opportunities and profits, which should be seen as a best practice approach for all profit-driven companies.
Capitalism - with its single line approach promoting profit and its 'unicorns' - has to adjust to take more ownership of societal problems. However, we can see a shift of companies adopting the triple bottom line approach into their business models where 'zebras' are the new benchmark and are critical to affect sustainable change for a better tomorrow. Changes are required on both sides (demand and supply side) to truly effectuate sustainable change. It can either be achieved through closer collaboration among all supply chain actors, or the platforms can nudge both sides into more desired habits to create a sustained impact.

\section{Limitation and Further Research}

While IS literature has shed much light on digital platforms, those with a social purpose and their integration in the supply chain have not been considered. Building on interviews with various platforms tackling the inefficiencies of the food supply chain, a categorization was developed, aimed at understanding the potential impacts they may have on the food supply chain. This research should be considered a snapshot of the current food supply chain and the impact that emerging local platforms create in a Nordic country which serves as an empirical example. When combining supply chain management with digital platforms, platforms have the potential to rupture power asymmetries and coordination from focal actors. Through digital platforms, new sources of industry data can be accessed that improve the coordination and efficiency of the supply chain. Digital platforms might bring transparency and complementary relationships among actors, as well as resolve power asymmetries and the coordination power of focal actors. Whereas, SCM is typically dominated by a top-down view from the focal firm to its dyadic partners [35], digital platforms are more prone to a bottom-up approach of an ecosystems view. The digitization of supply chains creates areas of conflict, as the common governance structures of supply chains change.

In particular Redistributors and Alterationist build an indication for change in the supply chain. the capability builder category is rather scarce at that moment and needs further investigation. It might also be possible that more than three platform types develop. The nature of case studies restricts the generalization of the results which should be seen as early indications of potential impact on the food supply chain. The dimensions showed some overlapping of categories, however there are also differences between each category which need to be examined. 
Further research should build on the three identified classifications for digital platforms with a social purpose (Alterationists, Redistributor, Capability Builder) and investigate through a longitudinal study the impact in the food supply chain. This might include an investigation of the respective potential in regard to long term competitiveness and profitability of the single models. It would be beneficial to further research differences within these platform categories and also to make an attempt to generalize these results for other industries and their supply chains.

\section{References}

[1] Financial Times, "FT Sets the Agenda with New Brand Platform," 2019. [Online]. Available: https://aboutus.ft.com/en-gb/announcements/ft-sets-theagenda-with-new-brand-platform/. [Accessed: 16-Sept2019].

[2] C. Meyer and J. Kirby, "Runaway capitalism," Harvard Business Review, 2012, 90(1-2), 66-75.

[3] J. Elkington, "Enter the triple bottom line," in The Triple Bottom Line: Does it All Add Up, (eds. R. J. Henriques), London, 2004.

[4] J. Elkington, "Partnerships from Cannibals with Forks: The Triple bottom line of 21st-Century Business," Environ. Qual. Manag., 1998, vol. 8, no. 1, pp. 37-51.

[5] I. Constantiou, A. Marton, and V. K. Tuunainen, "Four models of sharing economy platforms," MIS Q. Exec., 2017, vol. 16, no. 4, pp. 231-25.

[6] M.-H. Delmond, F. Coelho, A. Keravel, and R. Mahl, "How Information Systems Enable Digital Transformation: A Focus on Business Models and Value Co-Production," IUP J. Bus. Strateg. 2017, vol. XIV, no. 3, pp. 7-40.

[7] CBInsights, "Global Unicorn Club," 2018. Retrieved March 30, 2019 from [Online]. Available: https://www.cbinsights.com/research-unicorncompanies. [Accessed: 30-Mar-2019].

[8] M. Zepeda, "Zebra companies offer an alternative to the unicorn fantasy," 2017. [Online]. Available: https://qz.com/933681/start-ups-shouldnt-try-to-beunicorns-they-should-be-zebras/.

[9] Y, Oron, "Forget Unicorns. We Need More 'Zebra' Startups," 2018. [Online]. Available: from https://www.entrepreneur.com/article/322407. [Accessed: 1-Nov-2019].

[10] N. M. P. Bocken, S. W. Short, P. Rana, and S. Evans, "A literature and practice review to develop sustainable business model archetypes," J. Clean. Prod., 2014, vol. 65 , pp. 42-56.

[11] M. Kenney and J. Zysman, "The Rise of the Platform Economy,” Issues Sci. Technol., 2016, vol. 32, no. 2, pp. 61-69.

[12] C. Cennamo, "Competing in Digital Markets: A Platform-based Perspective," Academy of Management Perspectives, 2019.

[13] G. Parker, M. Van Alstyne, and S. P. Choudary, Platform Revolution. 2016.
[14] C. Alaimo, J. Kallinikos, and E. Valderrama, "Platforms as service ecosystems: Lessons from social media," J. Inf. Technol., 2019.

[15] F. Zhu and M. Iansiti, "Why Some Platforms Thrive and Others Don't," Harv. Bus. Rev., 2019, no. JanuarFebruary, pp. 1-11.

[16] M. Friedman, "The social responsibility of a business is to increase its profits"', The New York Times Magazine, September 13, 1970.

H. Kuang and W. H. Chou, "Research on Service Blueprint of Food Banks," Des. J., 2017, vol. 20, no. sup1, pp. 3425-3435.

[17] A. Xepapadeas \& A. de Zeeuw, "Environmental policy and competitiveness: the Porter hypothesis and the composition of capital," Journal of Environmental Economics and Management, 1999, vol. 37 no. 2, pp. 165-182.

S. Muggleton, "Alan Turing and the development of Artificial Intelligence.," AI Commun., 2014, vol. 27, no. 1, pp. 3-10.

[18] D. J. Teece, "Business models, business strategy and innovation," Long Range Plann., 2010, vol. 43, no. 2-3, pp. 172-194.

[19] T. Hindle, "Triple bottom line," 2009. [Online]. Available:

https://www.economist.com/news/2009/11/17/triplebottom-line. [Accessed: 20-Nov-2019].

S. Engert, R. Rauter, and R. J. Baumgartner, "Exploring the integration of corporate sustainability into strategic management: A literature review," J. Clean. Prod., 2016, vol. 112, pp. 2833-2850.

[20] A. M. Peredo and M. McLean, "Social entrepreneurship: A critical review of the concept," J. World Bus., 2006, vol. 41, no. 1, pp. 56-65.

[21] J. Austin, H. Stevenson, and J. Wei-Skillern, "Social and Commercial Entrepreneurship: Same, Different, or Both?," Entrep. Theory Pract., 2006, vol. 30, no. 1, pp. $1-20$.

[22] Project Drawdown, " Summary of Solutions by Overall Rank," 2020. [Online]. Available: https://www.drawdown.org/solutions/table-of-solutions. [Accessed: 02-Jun-2020].

[23] United Nation, " Goal 12: Sustainable Development Goals," (2020) [Online]. Available: https://sustainabledevelopment.un.org/sdg12. [Accessed: 12-May-2020].

[24] J. M. Aguilera, " Seligman Lecture 2005: food product engineering: building the right structures," Journal of the Science of Food and Agriculture, 2006, vol. 86, pp. 1147-1155.

[25] S. Nayyar, S. de Cleene, and L. Dreier, "Innovation with a Purpose: The role of technology innovation," World Econ. Forum, 2018, no. January, pp. 1-42.

[26] R.K. Yin, " Case study research, design and method. (4th Ed.)", Sage Publications Ltd. London, 2009.

[27] J. Aschemann-Witzel et al., "Key characteristics and success factors of supply chain initiatives tackling consumer-related food waste - A multiple case study," J. Clean. Prod., 2017, vol. 155, pp. 33-45.

[28] K. Täuscher and S. M. Laudien, "Understanding platform business models: A mixed methods study of 
marketplaces,” Eur. Manag. J., 2018, vol. 36, no. 3, pp. 319-329.

[29] A. Osterwalder and Y. Pigneur, Business Model Generation: A Handbook for visionaries, game changers and challengers, Jon Wiley \& Sons, New Jersey, 2010.

[30] A. Bryman and N. Bell, Business research methods (5th ed.). Oxford University Press, Oxford, 2015

[31] N. King, "Using interviews in qualitative research," in Essential Guide to Qualitative Methods in Organizational Research (eds. C. Cassell, and G. Symon, G), Sage, London, 2004.

[32] G. Gereffi, J. Humphrey, T. Sturgeon, " The Governance of Global Value Chains," Review of
International Political Economy, 2005, Vol. 12, No. 1, 78-104.

[33] P. Kraljic, "Purchasing must become supply management," Harvard Business Review, 1983, vol. 61 no. 5 , pp. 109-117.

[34] S. Ponte and P. Gibbon, "Quality standards, conventions and the governance of global value chains," Economy and Society, 2005, vol. 34, No. 1, pp. 1-31.

[35] G. Prockl, V. Bhakoo, and C. Wong, "Supply chains and electronic markets - impulses for value co-creation across the disciplines," Electron. Mark., 2017, vol. 27, no.

2 ,

pp.

135-14 